\title{
Alterações morfológicas e funcionais dos rins de cães com insuficiência renal crônica
}

[Morphologic and functional alterations of the kidneys of dogs with chronic renal failure]

\author{
M.H. Bueno de Camargo ${ }^{1}$, J R.E. Moraes $^{2 *}$, M.B. Carvalho ${ }^{2}$, G.C. Ferraro ${ }^{1}$, V. Palmeira Borges ${ }^{1}$ \\ ${ }^{1}$ Alunos de pós-graduação - FCAV-UNESP - Jaboticabal, SP \\ ${ }^{2}$ Faculdade de Ciências Agrárias e Veterinárias - UNESP \\ Via de Acesso Prof. Paulo Donato Castellane, s/n \\ 14884-900 - Jaboticabal, SP
}

\begin{abstract}
RESUMO
Alterações morfológicas de 11 casos de cães com insuficiência renal foram caracterizadas e classificadas de acordo com os padrões estabelecidos pela Organização Mundial de Saúde para seres humanos. Glomerulonefrite esclerosante difusa foi diagnosticada em $82,0 \%$ dos animais e nefrite intersticial crônica nos $18,0 \%$ restantes. Os tipos e freqüência das lesões identificadas foram similares às encontradas na literatura para a insuficiência renal crônica.
\end{abstract}

Palavras-chave: cão, glomerulonefrite, glomerulopatia, insuficiência renal, nefrite

\begin{abstract}
Morphologic alterations of 11 cases of dogs with renal failure were characterized and classified according to the patterns established by the World Health Organization for human beings. Diffuse sclerosing glomerulonephritis was diagnosed in $82.0 \%$ of the animals and chronic interstitial nephritis in the remaining $18.0 \%$. The types and frequencies of lesions were similar to the those noticed in the literature for chronic renal failure.
\end{abstract}

Keywords: dog, glomerulonephritis, glomerulopathy, renal failure, nephritis

\section{INTRODUÇÃO}

As doenças renais em cães são causadas por desordens de etiologia variada que induzem alterações estruturais e funcionais dos rins, diagnosticadas por meio do quadro clínico e da histopatologia (Spargos e Haas, 1994). Os estudos do tecido renal de cães com insuficiência renal são raros e, em sua maioria, estão relacionados aos quadros de doença renal familial ou de doenças específicas (Koeman et al., 1994; Rha et al., 2000).

Recebido em 17 de agosto de 2004

Aceito em 30 de novembro de 2005

*Autor para correspondência (corresponding author)

E-mail: jrmoraes@fcav.unesp.br

Apoio: CAPES
A doença glomerular é classificada de acordo com o padrão histológico das alterações renais sendo, portanto, o conhecimento da histopatologia necessário para a compreensão da doença. O termo glomerulonefrite é tradicionalmente empregado para descrever o grupo de doenças em que a lesão primária consiste em algum tipo de anomalia estrutural do glomérulo. Apesar do sufixo "ite", a maioria dos casos não é caracterizada por alterações inflamatórias. O dano ao glomérulo pode ser grave, levando a fibrose permanente com atrofia dos túbulos associados. Alternativamente, algumas condições produzem anormalidades temporárias e, seguindo-se à resolução, há restauração da função do néfron (Stevens e Lowe, 1998). 
O objetivo deste estudo foi o de caracterizar as alterações renais de cães com insuficiência renal crônica e classificá-las de acordo com os padrões indicados pela Organização Mundial de Saúde para seres humanos (Churg et al., 1985).

\section{MATERIAL E MÉTODOS}

Foram utilizados 11 cães de diferentes raças, de ambos os sexos, adultos, com insuficiência renal crônica, diagnosticada por características clínicas.

Amostras de urina e sangue foram coletadas por cateterização da uretra e por punção venosa, respectivamente. A urina foi analisada mediante o uso de densímetro e de tiras específicas para estudo de proteínas e densidade.

Uma fração de cada amostra de sangue destinouse à realização do hemograma, após a adição de anticoagulante. A contagem de hemácias e de leucócitos, a dosagem de hemoglobina e a determinação do hematócrito foram realizadas em contador eletrônico ${ }^{1}$. Para a contagem diferencial de leucócitos, foram utilizados esfregaços de sangue em lâminas de vidro, coradas com uma mistura de metanol, MayGrunwald e Giemsa.

Para a obtenção do soro, a fração restante do sangue foi acondicionada em tubo de ensaio e centrifugada a $1.500 \mathrm{rpm}$, por cinco minutos. As concentrações de uréia e creatinina séricas foram determinadas pelo método cinético ${ }^{2}$. Foram considerados insuficientes renais os animais que apresentaram valores acima de $65 \mathrm{mg} / \mathrm{dl}$ e $1,5 \mathrm{mg} / \mathrm{dl}$ de uréia e creatinina, respectivamente.

Alíquotas das amostras do soro foram submetidas à pesquisa de aglutininas antileptospiras, pela prova de soroaglutinação microscópica (SAM), sendo consideradas positivas as que apresentaram titulação superior a $1: 100$.

Após a morte natural, os animais foram encaminhados à necropsia para a avaliação macroscópica dos rins. Para a análise microscópica das lesões renais foi realizada

${ }^{1}$ COULTER AcT $8^{\circledR}$ - Diamond Diagnostics ${ }^{\mathcal{O}}$ - MA, USA.

${ }^{2}$ Kit Labtest $^{\circledR}-$ Labtest Diagnóstica ${ }^{\mathscr{C}}-$ MG, Brasil. coleta de fragmentos de aproximadamente $1,5 \mathrm{~cm}^{2}$, que foram imersos em solução de formaldeído $10 \%$, processados pelas técnicas habituais para inclusão em parafina e corados com hematoxilina-eosina, ácido periódico de Schiff (PAS) e tricrômico de Masson.

$\mathrm{Na}$ análise histológica, ao microscópio óptico, as alterações renais foram classificadas de acordo com os critérios definidos pela Organização Mundial de Saúde para os padrões morfológicos de glomerulonefrites (Churg et al., 1985). A localização, a distribuição e a intensidade das lesões glomerulares foram determinadas no tecido renal, sendo a freqüência expressa em porcentagem em relação ao número de glomérulos analisados (50 para cada animal). Para a classificação final, foram considerados os tipos de lesões glomerulares mais freqüentes e as lesões intersticiais.

\section{RESULTADOS E DISCUSSÃO}

O início e o conjunto dos eventos clínicos e bioquímicos, que ocorrem em pacientes com insuficiência renal crônica podem variar de acordo com a natureza, gravidade, duração e progressão da afecção subjacente. Freqüentemente, a uremia é o estado clínico em direção ao qual todas as afecções renais progressivas generalizadas convergem, sendo caracterizada por achados clínicos e laboratoriais diversos, que destacam a natureza polissistêmica da insuficiência renal crônica (Polzin et al., 1997).

A análise da densidade urinária apresentou alterações com valor máximo de 1,015 e mínimo de 1,007 (Fig. 1a). O valor médio observado e seu respectivo desvio-padrão foi $1,012 \pm 0,003$.

Observou-se proteinúria em oito animais, com valores variando de traços a três cruzes, e destes, seis eram portadores de glomerulonefrite esclerosante difusa (GED). Sedimentoscopia inativa ou caracterizada pela presença de poucos cilindros foi observada em todos os animais.

Os valores de hemácias em nove animais, bem como os de hemoglobina e hematócrito em 10 animais, foram mais baixos que os considerados normais para a espécie. Observou-se grande variação no número de leucócitos totais, sendo 
identificada leucocitose em quatro animais e leucopenia em dois. Na contagem diferencial, observou-se discreta neutrofilia em cinco animais e neutropenia apenas em um. Dois animais apresentaram linfocitose e nove monocitopenia.

Todos os valores de uréia e creatinina séricas estavam aumentados em relação aos de referência para a espécie (Fig. 1b, 1c). O valor médio e o desvio-padrão de creatinina sérica foram de $6,30 \pm 4,28 \mathrm{mg} / \mathrm{dl}$ e os de uréia foram de $305,43 \pm 162,36 \mathrm{mg} / \mathrm{dl}$, evidenciando diminuição da função renal, similares aos resultados já encontrados por Polzin e Osborne (1995) em cães.
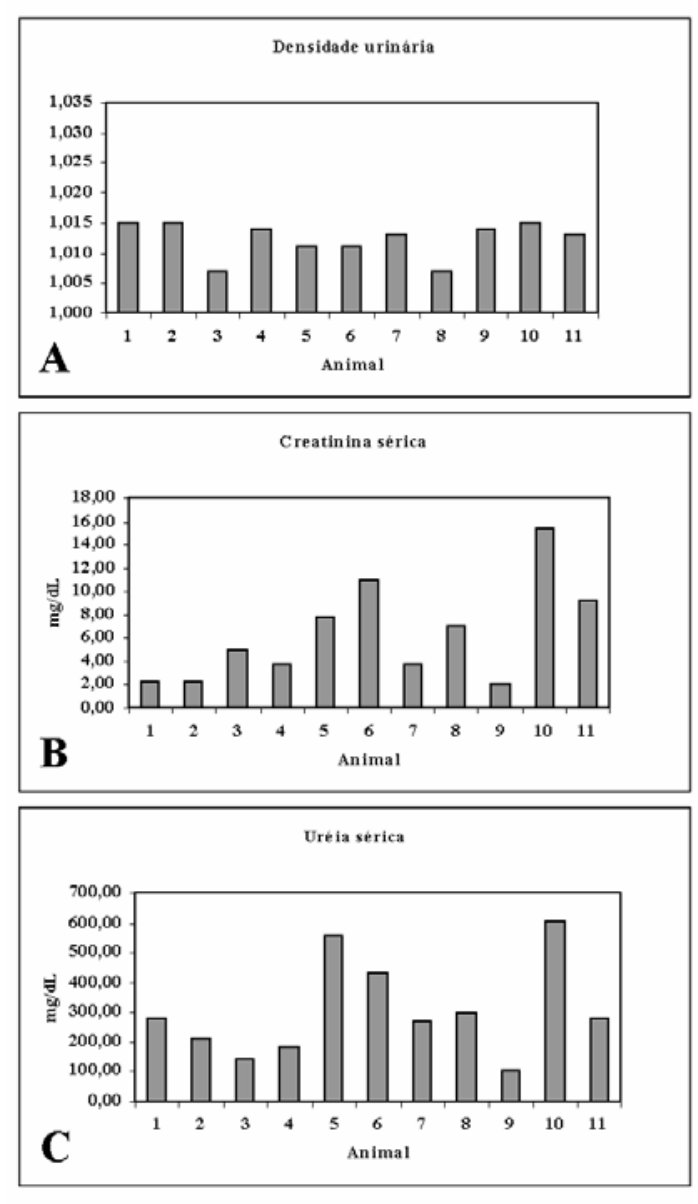

Figura 1. Valores individuais observados nos resultados dos exames dos 11 cães portadores de insuficiência renal crônica. (A) densidade urinária; (B) creatinina sérica $(\mathrm{mg} / \mathrm{dl})$ e $(\mathbf{C})$ uréia sérica $(\mathrm{mg} / \mathrm{dl})$.
$\mathrm{Na}$ análise macroscópica do parênquima renal, observaram-se superfície irregular, pontos de retração no parênquima com aderência de cápsula conectiva e calcificação, petéquias e congestão cortical e medular.

$\mathrm{Na}$ análise histopatológica, observou-se presença de bactérias em dois animais. Para a classificação microscópica das lesões renais, foram verificadas três classes de alterações: degenerativas, circulatórias e inflamatórias e/ou regenerativas.

As alterações degenerativas, as mais freqüentes, variaram desde lesões focais e discretas até difusas e graves, que indicavam degeneração e necrose tubular. Hialinização e calcificação foram identificadas na maioria dos animais. Dilatação tubular, fibrose intersticial, atrofia e esclerose glomerulares, hipercelularidade mesangial e tumefação de células endoteliais glomerulares também foram observadas (Fig. 2a, 2b).

Em todos os animais, as alterações inflamatórias foram caracterizadas pela presença predominante de leucócitos da fase crônica, como linfócitos e plasmócitos difusos no interstício renal (Fig. 2a, 2c). Freqüentemente foram observados corpos hialinos grandes, corados em róseo, indicando acúmulo de material proteináceo em túbulos renais (Fig. 3b). Gotículas coradas em róseo, também, foram observadas na luz de túbulos contornados, revelando coagulação protéica.

As alterações circulatórias mais freqüentes foram: congestão vascular difusa, hemorragias focais e trombose em grandes vasos (Fig. 2d). Alterações histológicas indicativas de reparação do tecido renal, como as fibroses (Fig. 2b), cistos de retenção urinária e edema glomerular (Fig. 2e, $2 \mathrm{f}$ ) foram observados.

Em relação à sorologia para leptospiras, três dos 11 animais apresentaram reação positiva, com títulos variando de 1:100 a 1:500, sendo um reagente ao sorovar Canicola e dois ao sorovar Icterohaemorrhagiae, dois dos sorovares mais comumente encontrados em cães com leptospirose (Greene, 1997). Segundo Searcy (1998), após a lesão hepática aguda, a localização desses microrganismos nos rins pode causar nefrite intersticial focal ou difusa. 


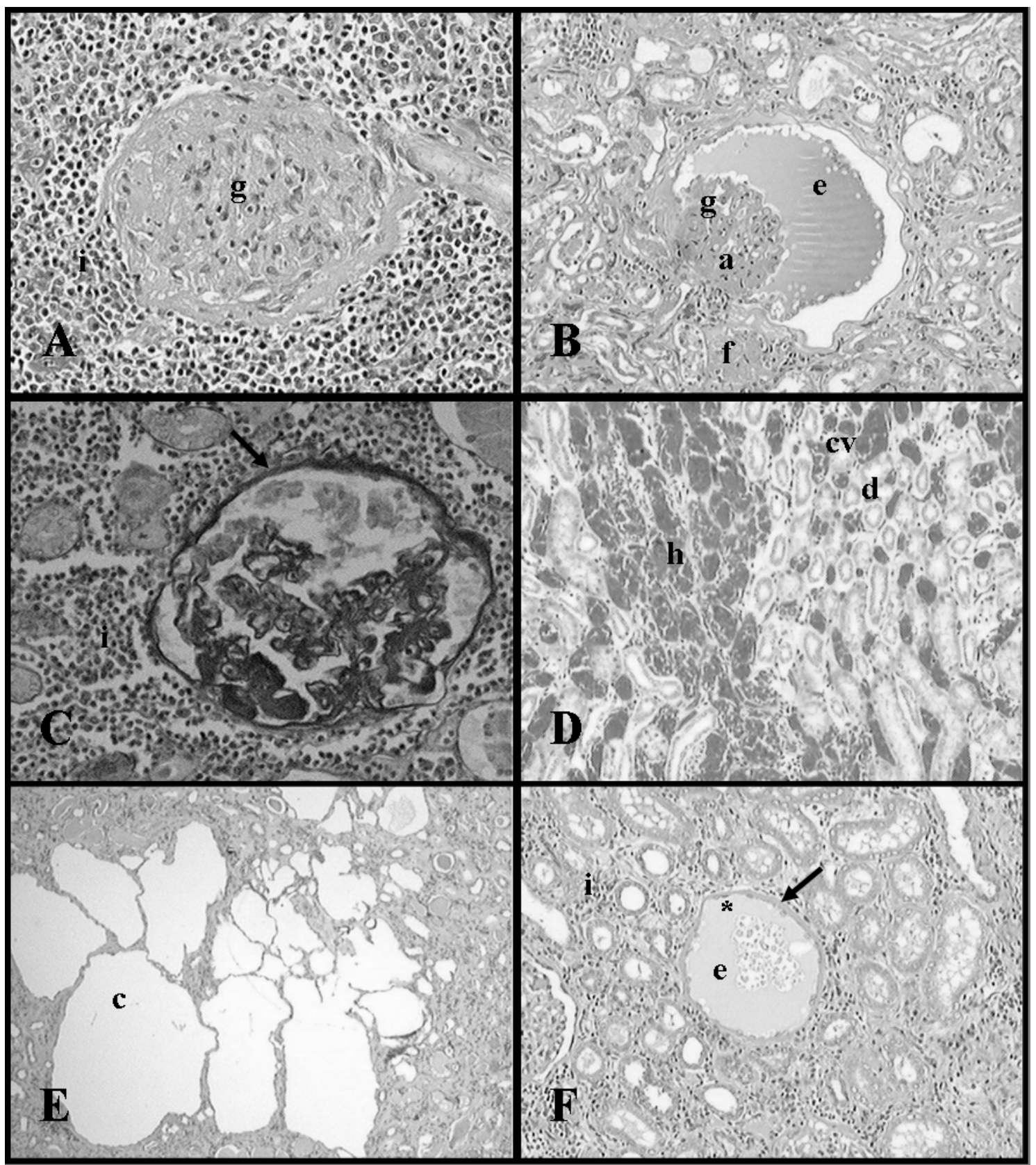

Figura 2. Fotomicrografias do tecido renal de cães portadores de insuficiência renal crônica. Verificar: esclerose glomerular (g); infiltrado mononuclear (i); edema glomerular (e); atrofia de tufo glomerular (a); fibrose intersticial (f); espessamento de cápsula glomerular (seta); congestão vascular (cv); degeneração tubular (d); hemorragia (h); grandes cistos de retenção urinária (c) e ausência de tufo glomerular $(*)$. Coloração: A, B, D, E, F: hematoxilina-eosina; C: ácido periódico de Schiff. Objetiva: A, C: 20×; B, D, $\mathrm{E}, \mathrm{F}: 10 \times$.

A presença de infiltrado inflamatório predominantemente mononuclear foi o principal achado microscópico. A maioria dos glomérulos (61\% em média) mostrou-se dentro dos padrões normais. As poucas lesões glomerulares presentes foram semelhantes às encontradas nos animais não reagentes às leptospiras, não sendo 
possível, assim, estabelecer relação entre essa reação com algum tipo de glomerulonefrite.

Os dois animais reagentes para o sorovar Icterohaemorrhagiae apresentaram lesões características de nefrite intersticial crônica (NIC), com presença de infiltrado inflamatório no interstício, acompanhada ou não de fibrina na parede capilar, fibrose nas junções corticomedulares, atrofia e necrose tubular, dilatação cística tubular e discreta lesão vascular (Fig. 2a, 2b, 3c).

Segundo Confer e Panciera (1998), a NIC está associada à fibrose renal, que ocorre mais freqüentemente como manifestação crônica da fase de resolução de uma lesão renal préexistente e, ao lado da lesão renal crônica, é o processo patológico mais comumente reconhecido em cães, podendo, quando grave, manifestar-se clinicamente como insuficiência renal e uremia. Microscopicamente, é caracterizada pelo aumento de tecido conectivo intersticial, atrofia dos túbulos e hialinização das suas membranas basais, com foco de linfócitos e plasmócitos difusos. Contudo, muitas afecções generalizadas crônicas dos rins, que se originam em vasos, glomérulos ou túbulos estão associadas a um grau considerável de inflamação e fibrose intersticiais, e o diagnóstico morfológico de uma NIC verdadeira sugere que o distúrbio subjacente se caracteriza, predominantemente, por anormalidades morfológicas e funcionais do tecido intersticial e que, se progressivas, podem induzir a alteração nos túbulos, glomérulos, e vasos renais (Polzin et al., 1997). Na leptospirose, o quadro morfológico da NIC é descrito como estádio final da doença (Wright et al., 1976; Lai et al., 1982).

O estudo histopatológico sistematizado, com base nos critérios da Organização Mundial de Saúde para classificação das alterações renais no homem, possibilitou diagnosticar GED em nove dos 11 animais. Essa foi caracterizada por esclerose glomerular, variando de obliteração segmentar a completa (Fig. 3a, 3b, 3e, 3f). Ocasionalmente, observaram-se aumento na celularidade glomerular e aderência entre o tufo e a cápsula glomerular, além de atrofia do glomérulo e fibrose difusa em regiões medulares e corticais (Fig. 3d). Esse fato permite inferir que a doença renal é de origem glomerular, embora o tempo de evolução não possa ser precisado.

A GED não caracteriza uma lesão específica, e sim representa o estágio final de vários tipos de glomerulopatias, com manifestação clínica de insuficiência renal crônica resultando em uremia (Churg et al., 1985; Confer e Panciera, 1998). Os resultados confirmam essas afirmações, pois $82 \%$ dos casos de doença renal estudados apresentaram lesões compatíveis com GED e evidências clínicas de uremia e proteinúria.

\section{CONCLUSÕES}

Os critérios de classificação propostos pela Organização Mundial de Saúde para glomerulonefrites no homem são plenamente aplicáveis para classificar as glomerulonefrites caninas. $\mathrm{O}$ cão mostrou-se um bom modelo de estudo para doença renal por apresentar lesões e comprometimento renal semelhantes aos observados no homem. Presença de proteinúria e concentrações elevadas de uréia e creatinina são indicativas de glomerulopatias.

\section{AGRADECIMENTOS}

Ao Laboratório de Histotecnologia, ao Serviço de Nefrologia e Urologia do Hospital Veterinário, ao Laboratório de Patologia do Hospital Veterinário e ao Laboratório de Leptospirose Animal - FCAV-UNESP Jaboticabal, SP, ao Departamento de Patologia da FMRP-USP, Ribeirão Preto, SP. 


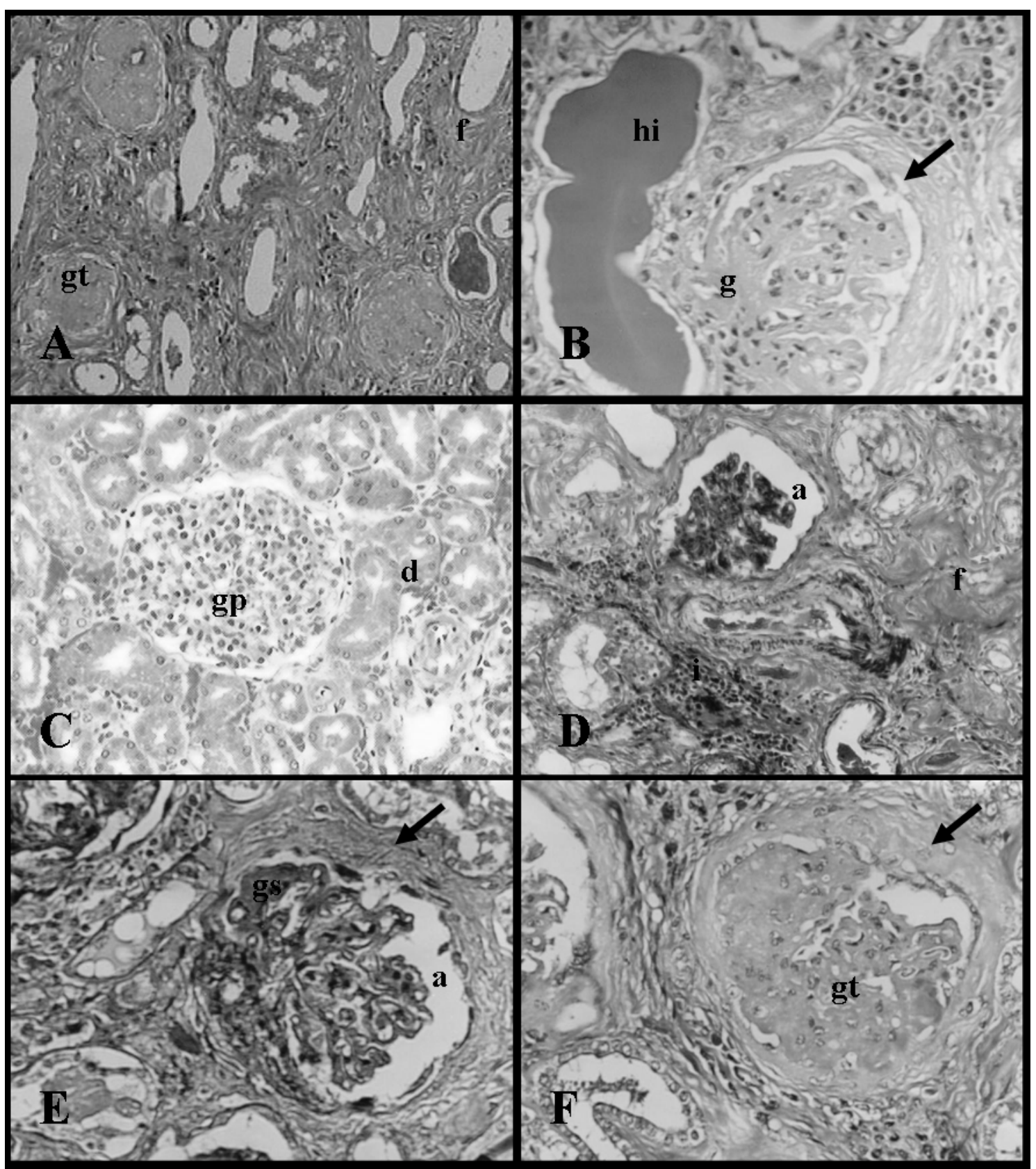

Figura 3. Fotomicrografias do tecido renal de cães portadores de insuficiência renal crônica. Verificar: esclerose glomerular total (gt); fibrose intersticial (f); esclerose glomerular (g); espessamento de cápsula glomerular (seta); hialinização (hi); glomerulonefrite membranoproliferativa (gp); degeneração tubular (d); atrofia de tufo glomerular (a); infiltrado mononuclear (i); esclerose glomerular segmentar focal (gs). Coloração: A, D, E, F: tricrômico de Masson; B, C: hematoxilina-eosina. Objetiva: A, C, D: 10×; B, E, F: $20 \times$. 


\section{REFERÊNCIAS BIBLIOGRÁFICAS}

CHURG, J.; BERNSTEIN, J.; GLASSOCK, R.J. Renal disease: classification and atlas of glomerular disease. 2.ed. New York: IgakuShoin, 1985. 541p.

CONFER, A.W.; PANCIERA, R.J. Sistema urinário. In: CARLTON, W.W.; McGAVIN, M.D. (Ed.). Patologia veterinária especial de Thomson. 2.ed. São Paulo: Artmed, 1998. p.228265.

GREENE, C.E. Moléstias bacterianas. In: ETTINGER, S.J.; FELDMAN, E.C. (Ed.). Tratado de medicina veterinária - moléstias do cão e do gato. 4.ed. São Paulo: Manole, 1997. v.1, p.538-539.

KOEMAN, J.P.; BIEWENGA, W.J.; GRUYS, E. Proteinuria associated with glomerulosclerosis and glomerular collagen formation in three Newfoundland dog littermates. Vet. Pathol., v.31, p.188-193, 1994.

LAI, K.N.; AARONS I.; WOODROFFE, A.J. et al. Renal lesions in leptospirosis. Aust. New Zeal. J. Med., v.12, p.276-279, 1982.

POLZIN, D.J.; OSBORNE, C.A. Pathophysiology of renal failure and uremia. In: OSBORNE, C.A.; FINCO, D.R. Canine e feline nephrology and urology. Baltimore: Williams e Wilkins, 1995. p.335-367.

POLZIN, D.J.; OSBORNE, C.A.; BARTGES, J.W. et al. Insuficiência renal crônica. In: ETTINGER, S.J.; FELDMAN, E.C. (Eds.) Tratado de medicina veterinária - moléstias do cão e do gato. 4.ed. São Paulo: Manole, 1997. v.2, p.2394-2431.

RHA, J.Y.; LABATO, M.A.; ROSS, L.A. et al. Familial glomerulonephropathy in a litter of beagles. J. Am. Vet. Med. Assoc., v.216, p.46-50, 2000.

SEARCY, G.P. Sistema hemopoético. In: CARLTON, W.W.; McGAVIN, M.D. (Eds). Patologia veterinária especial de Thomson. 2.ed. São Paulo: Artmed, 1998. p.312.

SPARGOS, B.H.; HAAS, M. The kidney. In: RUBIN, S.I.; FABER, J.L. Pathology. 2.ed. Philadelphia: J.B. Lippincott, 1994. p.804-865.

STEVENS, A.; LOWE, J. Doenças do sistema urinário. In: Patologia. 2.ed. São Paulo: Manole, 1998. p.317-349.

WRIGHT, N.G.; FISHER, E.W.; MORRISON, W.I. Chronic renal failure in dogs: a comparative clinical and morphological study of chronic glomerulonephritis and chronic interstitial nephritis. Vet. Rec., v.98, p.288-293, 1976. 